Original Research Paper

\title{
The Evaluation of the Groundwater Influence on the Stress and Strain Behavior around a Tunnel by Analytical Methods
}

\author{
Pierpaolo Oreste \\ Department of Environmental, Land and Infrastructural Engineering, \\ Politecnico di Torino (Italy) Corso Duca degli Abruzzi 24, I-10129 Torino, Italy
}

\author{
Article history \\ Received: 08-04-2015 \\ Revised: 20-08-2015 \\ Accepted: 10-02-2015 \\ Email: pierpaolo.oreste@polito.it
}

\begin{abstract}
The presence of an aquifer in the soil causes a change in a relevant way of the stability conditions of a tunnel. The flow of water in the pores, in fact, modifies the stress and strain state of the soil and causes an increase in the thickness of the plastic zone. As a result the loads transmitted on the lining increase. In this study a calculation procedure by finite differences method, able to determine the stress and strain state of the soil in the presence of the water flow in the pores, is presented. More particularly, using the proposed procedure, it is possible to determine the convergence-confinement curve of the tunnel and the trend of the plastic radius varying the internal pressure. A calculation example is used to detect the great influence that the presence of the aquifer has on the stress and strain state of the soil and on the pressure-displacement relationship of the tunnel wall.
\end{abstract}

Keywords: Tunnel Stability, Deep Tunnel, Circular Tunnel, Underwater Tunnels, Convergence-Confinement Curve, Groundwater, Tunnel Support, Excavation Face, Pore Pressure, Stress and Strain Around the Tunnel

\section{Introduction}

The groundwater presence in the soil has an important effect on the stability of a tunnel. The flow of water towards the tunnel, in fact, substantially alters the stress state around the void perimeter (Bobet, 2003; Fahimifar et al., 2014; Fernandez and Moon, 2010; Haack, 1991; Hwang and Lu, 2007), increasing the thickness of any existing plastic zone. As a result, the loads acting on the lining increase.

Even at the face, the static conditions are exacerbated by the presence of a groundwater flow towards the tunnel, which may lead to the soil breakage for a portion more or less extended ahead of the face (Oreste, 2013).

It is, therefore, fundamental to detect critical conditions for the tunnel stability, when an aquifer is present (Carranza-Torres and Zhao, 2009; Nam and Bobet, 2006; Li et al., 2014; Wang et al., 2008).

The numerical methods, both two-dimensional and three-dimensional ones (Do et al., 2014; 2015; Oreste, 2007), are able to study in detail the stress and strain state around a tunnel and in the support structure. In the presence of groundwater and of water flow in a porous medium, it is necessary to provide coupled numerical analysis, in which the stress and strain analysis is developed in parallel to the water flow analysis. For these reasons, the numerical methods, especially the three-dimensional ones, appear to be very slow when they have to analyze the behavior of a tunnel in a porous medium with groundwater.

Through the analytical calculation methods, it is possible to approach the study of some aspects of tunnel static easily and fast. Several analytical methods are available in the literature and are able to assess the stress and strain state around a tunnel (Oreste, 2003), ahead of the excavation face (Oreste, 2009a), in the support and reinforcement structures (Oreste, 2008; Osgoui and Oreste, 2007; 2010), when it is possible to introduce some simplifying assumptions of the problem in the calculation. These methods are characterized by a relatively high speed of calculation, which allows one to develop extensive parametric analyzes, probabilistic analyzes (Oreste, 2005a; 2014a) or back-analyzes (Oreste, 2005b).

In this study is presented a numerical solution by finite difference method that allows to analyze in detail the stress and strain state of the soil around the tunnel, in the presence of a water flow in the pores. From the calculation it is possible to determine the convergenceconfinement curve of the tunnel, the evolution of the plastic radius varying the total internal pressure applied 
to the tunnel walls, the stresses and displacements that develop in the soil around the tunnel, for a certain total pressure applied to the walls.

A calculation example for a specific case will illustrate the influence of the groundwater flow in the soil pores on the convergence-confinement curve of the tunnel and on the stress and strain state of the soil.

\section{Materials and Methods}

The analysis of the behavior of a circular and deep tunnel can be developed through the convergenceconfinement method for the cylindrical geometry (Ribacchi and Riccioni, 1977; Lembo-Fazio and Ribacchi, 1986; Panet, 1995; Orestes, 2009b). This method allows to obtain the relationship between the radial displacement of the tunnel wall and the internal pressure applied to the tunnel perimeter. Proceeding with then the intersection of the convergenceconfinement curve of the tunnel with the reaction line of the support, one can determine the final displacement of the tunnel wall and the load acting on the support structure (Oreste, 2014b).

Il metodo delle curve caratteristiche si basa sulle seguenti fondamentali equazioni (Ribacchi and Riccioni, 1977; Lembo-Fazio and Ribacchi, 1986; Panet, 1995): L'equazione di equilibrio assialsimmetrico delle forze nella direzione radiale (Equation 1) e le due equazioni di congruenza delle deformazioni (Equation 2). Inoltre, per il terreno a comportamento elastico al contorno della galleria valgono le due equazioni dell'elasticità per il campo di deformazione piano e geometria assialsimmetrica, mentre per la porzione di terreno a comportamento plastico (all'interno della fascia plastica), sono validi il criterio di rottura e la relazione tra le deformazioni principali plastiche (la cosiddetta legge di flusso) (Ribacchi and Riccioni, 1977; Lembo-Fazio and Ribacchi, 1986; Panet, 1995).

The convergence-confinement method is based on the following fundamental equations (Ribacchi and Riccioni, 1977; Lembo-Fazio and Ribacchi, 1986; Panet, 1995): The equation of axisymmetric equilibrium of forces in the radial direction (Equation 1) and the two equations of strain congruence (Equation 2). Also, for the soil with elastic behavior around the tunnel the two equations of the elasticity, for the plane field strain and axisymmetric geometry, can be applied; while, for the soil portion with elastic-plastic behavior (inside the plastic zone), the failure criterion and the relationship between the main plastic strains (the socalled flow law) are valid (Ribacchi and Riccioni, 1977; Lembo-Fazio and Ribacchi, 1986; Panet, 1995):

$$
\frac{d \sigma_{r}}{d r} \cong \frac{\left(\sigma_{\vartheta}-\sigma_{r}\right)}{r}
$$

$\varepsilon_{\vartheta}=\frac{u}{r}$

$\varepsilon_{r}=\frac{d u}{d r}$

Where:

$\sigma_{\mathrm{r}}$ and $\sigma_{\vartheta}=$ The radial and circumferential stresses

$\varepsilon_{\mathrm{r}}$ and $\varepsilon_{\vartheta}=$ The radial and circumferential strains

$u \quad=$ The radial displacement of the soil (positive when directed towards the tunnel centre)

The relationship between the radial displacement of the tunnel wall $u_{R}$ and the applied internal pressure $\sigma_{R}$ depends on the presence or not of a plastic zone around the tunnel (Oreste, 2014b):

$u_{R}=f\left(E, v, R, p_{0}, \sigma_{R}\right)$ for soil with an

elastic behavior (absence of a plastic zone)

$u_{R}=f\left(E, v, R, p_{0}, \sigma_{R}, c, \varphi, \psi\right)$ when a zone of

the soil with elastic - plastic behavior is present

Where:

$E$ and $v=$ Elastic modulus and Poisson ratio of the soil

$R \quad=$ Tunnel radius

$p_{0} \quad=$ Lithostatic pressure

$c$ and $\varphi=$ Soil cohesion and friction angle

$\psi \quad=$ Soildilatancy angle

$\sigma_{R} \quad=$ Radial stress applied to the tunnel perimeter

In general, there is always a stretch of the convergence-confinement curve with an elastic behavior, defined by Equation $3 \mathrm{a}$, for values of $\sigma_{R}$ greater than a certain critical pressure $\sigma_{R p l}$ (Equation 4). For values of $\sigma_{R}$ lower than $\sigma_{R p l}$ (if $\sigma_{R p l}$ is positive), the relationship between $u_{R}$ and $\sigma_{R}$ is defined by Equation $3 \mathrm{~b}$ :

$$
\sigma_{R p l}=\frac{2 \cdot p_{0}-\sigma_{c}}{\left(N_{\varphi}+1\right)}
$$

With:

$N_{\varphi}=\frac{1+\operatorname{sen} \varphi}{1-\operatorname{sen} \varphi} ; \sigma_{c}=\frac{2 \cdot c \cdot \cos \varphi}{1-\operatorname{sen} \varphi}$

When $\sigma_{R p l}$ is negative, the convergence-confinement curve is entirely described by Equation 3 and has a linear shape for its entire extension.

In the presence of groundwater in the soil, it is necessary to refer to effective stresses and no longer to the total stresses. In addition, the e Equation 1 is modified, as the forces acting on the infinitesimal soil element around the tunnel are different (Fig. 1). 


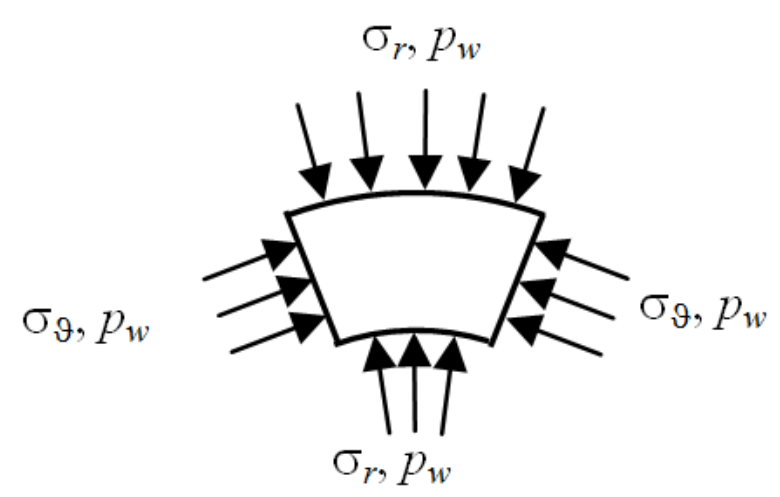

Fig. 1. Stresses acting on the infinitesimal soil element around the tunnel. Legend: $\sigma_{\vartheta}$ and $\sigma r$ : Circumferential and radial stresses; $p_{w}$ : Water pressure in the soil pores

In fact, proceeding to the equilibrium of forces in the radial direction, we obtain:

$$
\begin{aligned}
& \sigma_{r} \cdot r \cdot d \vartheta+p_{w} \cdot r \cdot d \vartheta+2 \cdot \sigma_{\vartheta} \cdot d r \cdot \operatorname{sen}\left(\frac{d \vartheta}{2}\right) \\
& +2 \cdot p_{w} \cdot d r \cdot \operatorname{sen}\left(\frac{d \vartheta}{2}\right) \cong\left(\sigma_{r}+\frac{d \sigma_{r}}{d r} \cdot d r\right) \cdot(r+d r) \cdot d \vartheta \\
& +\left(p_{w}+\frac{d p_{w}}{d r} \cdot d r\right) \cdot(r+d r) \cdot d \vartheta
\end{aligned}
$$

Where:

$\mathrm{d} \vartheta=$ Infinitesimal angle that indicates the width of the infinitesimal element of Fig. 1

$r=$ Distance from the tunnel centre

$\mathrm{p}_{\mathrm{w}}=$ Water pressure in the soil pores

From which:

$$
\begin{aligned}
& \sigma_{r} \cdot r \cdot d \vartheta+p_{w} \cdot r \cdot d \vartheta+2 \cdot \sigma_{\vartheta} \cdot d r \cdot \operatorname{sen}\left(\frac{d \vartheta}{2}\right) \\
& +2 \cdot p_{w} \cdot d r \cdot \operatorname{sen}\left(\frac{d \vartheta}{2}\right) \cong \frac{d \sigma_{r}}{d r} \cdot d r \cdot r \cdot d \vartheta+\sigma_{r} \cdot d r \cdot d \vartheta \\
& +\frac{d p_{w}}{d r} \cdot d r \cdot r \cdot d \vartheta+p_{w} \cdot d r \cdot d \vartheta
\end{aligned}
$$

and, therefore:

$$
\begin{aligned}
& \sigma_{\vartheta} \cdot d r \cdot d \vartheta+p_{w} \cdot d r \cdot d \vartheta \cong \frac{d \sigma_{r}}{d r} \cdot d r \cdot r \cdot d \vartheta \\
& +\sigma_{r} \cdot d r \cdot d \vartheta+\frac{d p_{w}}{d r} \cdot d r \cdot r \cdot d \vartheta+p_{w} \cdot d r \cdot d \vartheta
\end{aligned}
$$
2014):

Finally, is obtained (Fahimifar et al., 2014; Li et al.,

$$
\frac{d \sigma_{r}}{d r} \cong \frac{\left(\sigma_{\vartheta}-\sigma_{r}\right)}{r}-\frac{d p_{w}}{d r}
$$

To assess in detail the trend of the water pressure $p_{w}$ with the distance from the tunnel center, an analysis of the water flow has to be developed. It is useful to consider the steady-state condition (constant flow over time). More particularly, for the Darcy law is (Bear, 1972; Wang et al., 2008):

$$
v=k \cdot i=k \cdot \frac{d h}{d r}=\frac{k}{\gamma_{w}} \cdot \frac{d p_{w}}{d r}
$$

Where:

$v=$ Water velocity in the radial direction

$k=$ Permeability coefficient of the soil

$i=$ Hydraulic gradient

$h=$ Piezometric height

$\gamma_{\mathrm{w}}=$ Specific weigth of water

and, then, the flow of water towards the tunnel Q (considering 1 meter depth in the geometry of the problem) is given by the following relation:

$$
\frac{k}{\gamma_{w}} \cdot \frac{d p_{w}}{d r} \cdot(2 \cdot \pi \cdot r)=Q
$$

From which:

$$
\frac{d p_{w}}{d r}=\frac{\gamma_{w}}{k} \cdot \frac{Q}{(2 \cdot \pi \cdot r)}
$$

Which, integrated by $\mathrm{R}$ (tunnel radius), where the water pressure at the lining extrados is $p_{w, \text { ext }}$, up to the generic distance $r$, where the water pressure is $p_{w}$, leads to the following relation:

$$
p_{w}=\frac{\gamma_{w}}{k} \cdot \frac{Q}{2 \cdot \pi} \cdot \ln \left(\frac{r}{R}\right)+p_{w, e x t}
$$

To obtain the value of $p_{w, \text { ext }}$, it is necessary to analyze the situation inside the tunnel lining, characterized by a thickness $\mathrm{t}$ and by a permeability coefficient $k_{\text {sup }}$. The Equation 7 now becomes:

$\frac{d p_{w}}{d r}=\frac{\gamma_{w}}{k_{\text {sup }}} \cdot \frac{Q}{(2 \cdot \pi \cdot r)}$

The Equation 9, integrated by (R-t) (lining intrados, where $p_{w}$ is nil) to $\mathrm{R}$ (lining extrados, where the water pressure is equal to $\mathrm{p}_{\mathrm{w}, \mathrm{ext}}$ ), provides the following equation:

$$
p_{w, \text { ext }}=\frac{\gamma_{w}}{k_{\text {sup }}} \cdot \frac{Q}{2 \cdot \pi} \cdot \ln \left(\frac{R}{R-t}\right)
$$

Substituting Equation 10 in Equation 8, the expression of $p_{w}$ in the soil can be rewritten in the following way: 


$$
\begin{aligned}
& p_{w}=\frac{\gamma_{w} \cdot Q}{2 \cdot \pi} \cdot\left[\frac{1}{k} \cdot \ln \left(\frac{r}{R}\right)+\frac{1}{k_{\text {sup }}} \cdot \ln \left(\frac{R}{R-t}\right)\right] \\
& =\frac{\gamma_{w} \cdot Q}{2 \cdot \pi \cdot k} \cdot\left[\ln \left(\frac{r}{R}\right)+\frac{k}{k_{\text {sup }}} \cdot \ln \left(\frac{R}{R-t}\right)\right]
\end{aligned}
$$

Assuming $p_{w}$ reaches the water pressure $p_{w, 0}$ (in undisturbed conditions) to the tunnel depth, for a distance $r=\alpha \cdot R$, the flow rate $Q$ value is obtained:

$$
Q=\frac{p_{w, 0} \cdot 2 \cdot \pi \cdot k}{\gamma_{w} \cdot\left[\ln (\alpha)+\frac{k}{k_{\text {sup }}} \cdot \ln \left(\frac{R}{R-t}\right)\right]}
$$

and, therefore, the expression of $p_{w}$ can be rewritten as:

$$
p_{w}=p_{w, 0} \cdot \frac{\ln \left(\frac{r}{R}\right)+\frac{k}{k_{\text {sup }}} \cdot \ln \left(\frac{R}{R-t}\right)}{\ln (\alpha)+\frac{k}{k_{\text {sup }}} \cdot \ln \left(\frac{R}{R-t}\right)}
$$

The water pressure on the tunnel wall, in correspondence of the lining extrados, therefore is:

$$
p_{w, e x t}=p_{w, 0} \cdot \frac{\frac{k}{k_{\text {sup }}} \cdot \ln \left(\frac{R}{R-t}\right)}{\ln (\alpha)+\frac{k}{k_{\text {sup }}} \cdot \ln \left(\frac{R}{R-t}\right)}
$$

The derivative $d p_{w} / d r$ takes, therefore, the following form:

$$
\frac{d p_{w}}{d r}=\frac{p_{w, 0}}{r \cdot\left[\ln (\alpha)+\frac{k}{k_{\text {sup }}} \cdot \ln \left(\frac{R}{R-t}\right)\right]}
$$

\section{Results}

To analyze the trend of stresses, strains and radial displacements around the tunnel varying $r$ and in the presence of groundwater, it should proceed with a numerical solution using the finite differences method. This solution, starting from a great distance from the tunnel center (high value of $r$ ), for which is assumed nil the derivative $d p_{w} / d r$ and $\sigma_{r}$ is put equal to a certain percentage of $p_{0}$, allows to calculate the radial and circumferential stresses and the radial displacements for concentric rings, moving towards the tunnel wall, where $r=R$. At the generic ring the following calculation steps are developed:

- Evaluation of the radial stress $\sigma_{r}$ on the inner radius of the ring from the derived $d \sigma_{r} /$ drcalculated on the outer radius in the previous step
- Evaluation of the radial displacement $\mathrm{u}$ on the inner radius of the ring from the derivative $\mathrm{du} /$ drcalculated at the outer radius in the previous step

- Determination of the circumferential stress $\sigma_{\vartheta}$ on the inner radius of the ring, on the basis of the following equations (Equation 16a if the elasticity theory is valid, Equation $16 \mathrm{~b}$ if the ring has elastic-plastic behavior) (Ribacchi and Riccioni, 1977):

$$
\begin{aligned}
& \varepsilon_{\vartheta}=\frac{1}{E} \cdot\left[\left(\sigma_{\vartheta}-p_{0}\right) \cdot\left(1-v^{2}\right)-\left(\sigma_{r}-p_{0}\right) \cdot\left(v+v^{2}\right)\right]=\frac{u}{r} \\
& \sigma_{\vartheta}=\sigma_{r} \cdot N_{\varphi}+\sigma_{c}
\end{aligned}
$$

- Determination of the derivative du/dron the inner radius of the ring, on the basis of the following equations (Equation 17a if the elasticity theory is valid, Equation $17 \mathrm{~b}$ if the ring has elastic-plastic behavior) (Ribacchi and Riccioni, 1977):

$$
\varepsilon_{r}=\frac{d u}{d r}=\frac{1}{E} \cdot\left[\left(\sigma_{r}-p_{0}\right) \cdot\left(1-v^{2}\right)-\left(\sigma_{\vartheta}-p_{0}\right) \cdot\left(v+v^{2}\right)\right]
$$

$$
\varepsilon_{r}+N_{\psi} \cdot \varepsilon_{\vartheta}=\frac{d u}{d r}+N_{\psi} \cdot \frac{u}{r}
$$$$
=\frac{1}{E} \cdot\left[\begin{array}{l}
\left(\sigma_{r}-p_{0}\right) \cdot\left(1-v^{2}-N_{\psi} \cdot v-N_{\psi} \cdot v^{2}\right) \\
+\left(\sigma_{\vartheta}-p_{0}\right) \cdot\left(N_{\psi}-N_{\psi} \cdot v^{2}-v-v^{2}\right)
\end{array}\right]
$$

- Determination of the derivative $d \sigma_{r} /$ dron the inner radius of the ring, on the basis of Equation 5, both if the elasticity theory is valid and the ring has elasticplastic behavior (Fahimifar et al., 2014; Li et al., 2014)

- Comparison of the circumferential stress $\sigma_{\vartheta}$ calculated in step 3 with the soil strength for the existing confinement stress $\sigma_{r}$ : In the case the circumferential stress is greater than the soil strength, the starting of the soil plasticization is detected and the plastic radius (distance from the tunnel center of the extreme outer of the plastic zone)is evaluated

Continuing the procedure for concentric rings until reaching the tunnel wall $(\mathrm{r}=\mathrm{R})$, a pair of values $\sigma_{R^{-}} u$ is obtained; the series of the $\sigma_{R-u}$ pairs each corresponding to a different initial value of $\sigma_{R}$ at a great distance from the tunnel center, allows to draw the convergenceconfinement curve when the groundwater is present. It is also possible to identify the plastic radius, that is the value of the distance from the tunnel center where the transition from elastic to elastic-plastic behavior is detected.

By adopting the above solution to the case of a circular tunnel of radius $\mathrm{R}=3 \mathrm{~m}$ and $75 \mathrm{~m}$ deep, it is possible to determine the influence of the groundwater presence on the convergence-confinement curve of the 
tunnel. The tunnel is excavated in a soil having cohesion $\mathrm{c}=0.2 \mathrm{kPa}$, friction angle $\varphi=20^{\circ}$, dilatancyangle $\psi=$ $20^{\circ}$, elastic modulus $\mathrm{E}=350 \mathrm{MPa}$, Poisson's ratio $v=$ 0.3 and the specific weight of the soil $\gamma=20 \mathrm{kN} / \mathrm{m}^{3}$. It is assumed the presence of a lining with a thickness of 0.3 $\mathrm{m}$ and a permeability coefficient $k_{\text {sup }}$ equal to $0.1 \cdot \mathrm{k}$ (with $\mathrm{k}$ permeability coefficient of the soil). The parameter $\alpha$ was assumed equal to 20: That is, it is considered that at a distance equal to $20 \cdot \mathrm{R}$ the piezometric height of the water table reaches the initial unperturbed value.

Two conditions of absence and presence of groundwater (with the free surface coincident with the ground surface) were evaluated. In the first case, the litho static stress state in the undisturbed conditions is equal to $1.5 \mathrm{MPa}$; in the second case, it is equal 0.75 $\mathrm{MPa}$ in terms of effective stresses, since $p_{w, 0}=0.75 \mathrm{MPa}$.
The water pressure at the lining extrados $\left(p_{w, \text { ext }}\right)$, calculated by Equation 14, is equal to $0.195 \mathrm{MPa}$.

Figure 2 shows the convergence-confinement curve of the tunnel obtained from the proposed calculation procedure for the case of absence (DC-dry condition) and presence (GF-groundwater flow) of groundwater. Figure 3 shows the trend of the plastic radius (extreme distance from the tunnel center of the plastic zone) varying the internal pressure on the tunnel perimeter. In Figure 4 is shown the trend of the soil stresses and the water pressure varying the distance from the tunnel center, for a nil total pressure on the tunnel wall; Fig. 5, finally, shows the trend of the radial displacements in the soil varying the distance from the tunnel center, for the two examined conditions (DC and GF) and for a nil total pressure applied on the tunnel wall.

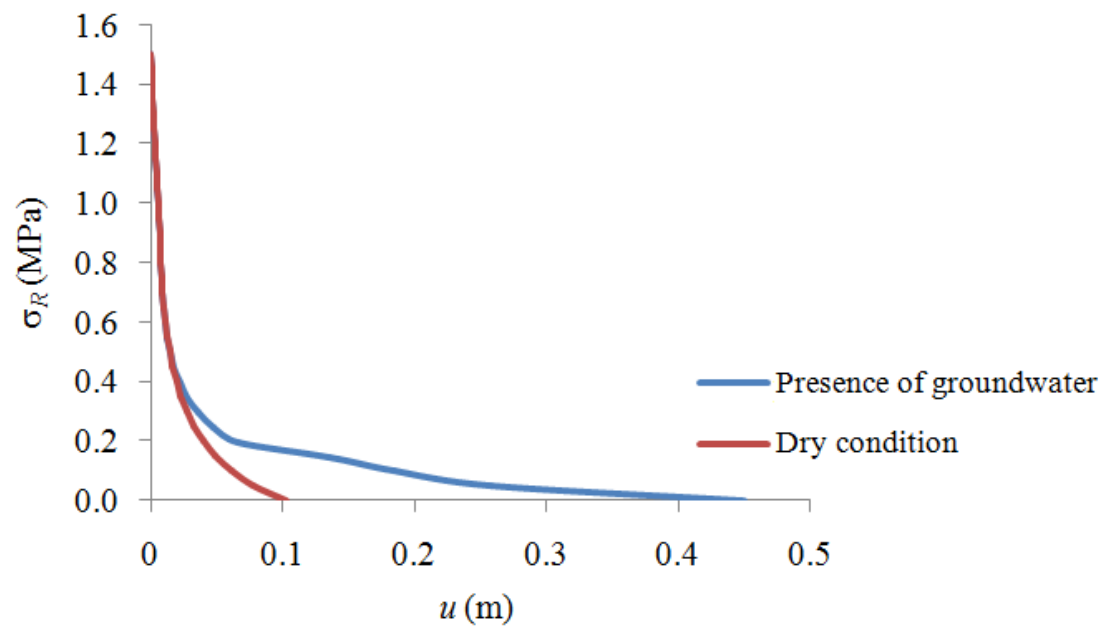

Fig. 2. Convergence-confinement curve of the tunnel for the Dry Condition (DC) and in presence of the Groundwater (GF) in the examined case of a tunnel having a radius equal to $3 \mathrm{~m}$

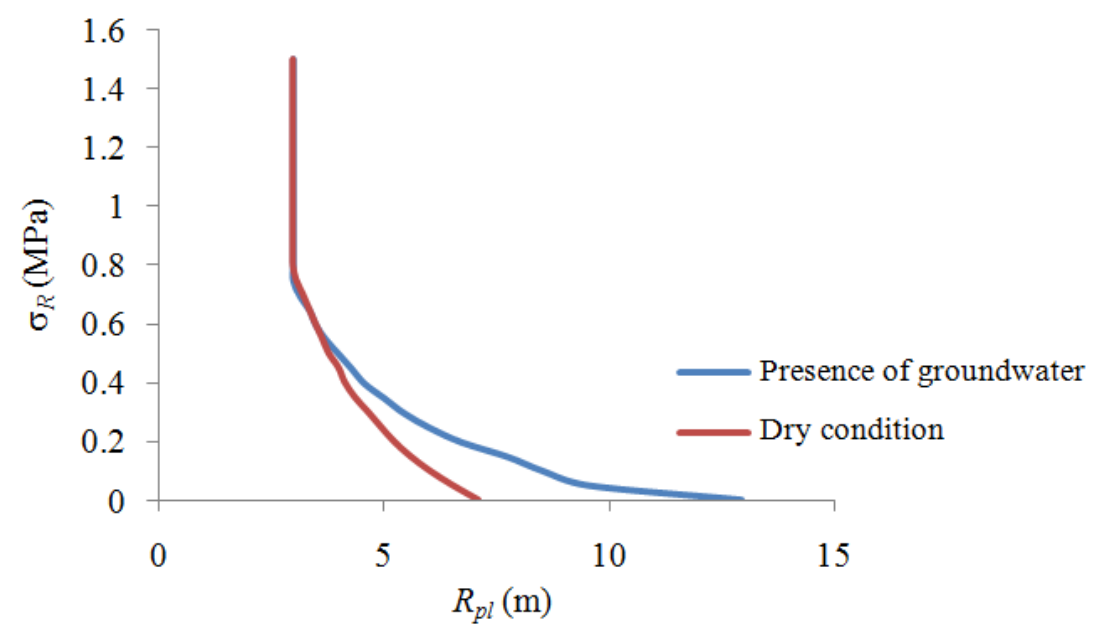

Fig. 3. Trend of the plastic radius varying the total internal pressure for the Dry Condition (DC) and in presence of the Groundwater (GF) in the examined case of a tunnel having a radius equal to $3 \mathrm{~m}$ 


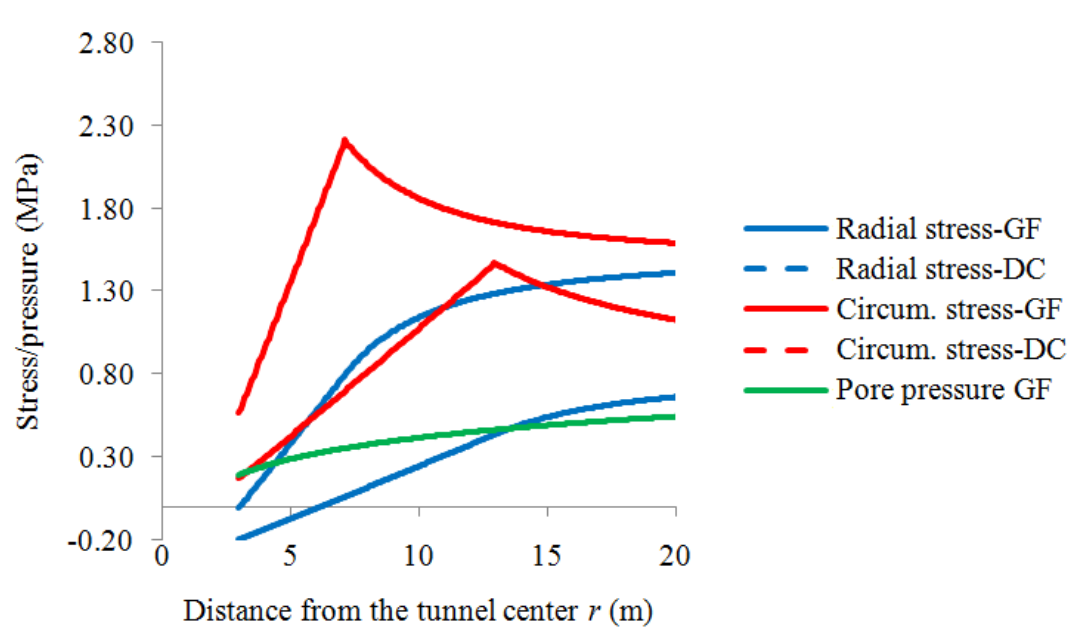

Fig. 4. Trend of the radial $\sigma_{r}$ and circumferential $\sigma_{\vartheta}$ stresses and of the pore pressure $p_{w}$ varying the distance from the tunnel center $r$, for the Dry Condition (DC) and in presence of the Groundwater (GF) in the examined case of a tunnel having a radius equal to $3 \mathrm{~m}$. The internal total pressure applied to the tunnel perimeter is nil

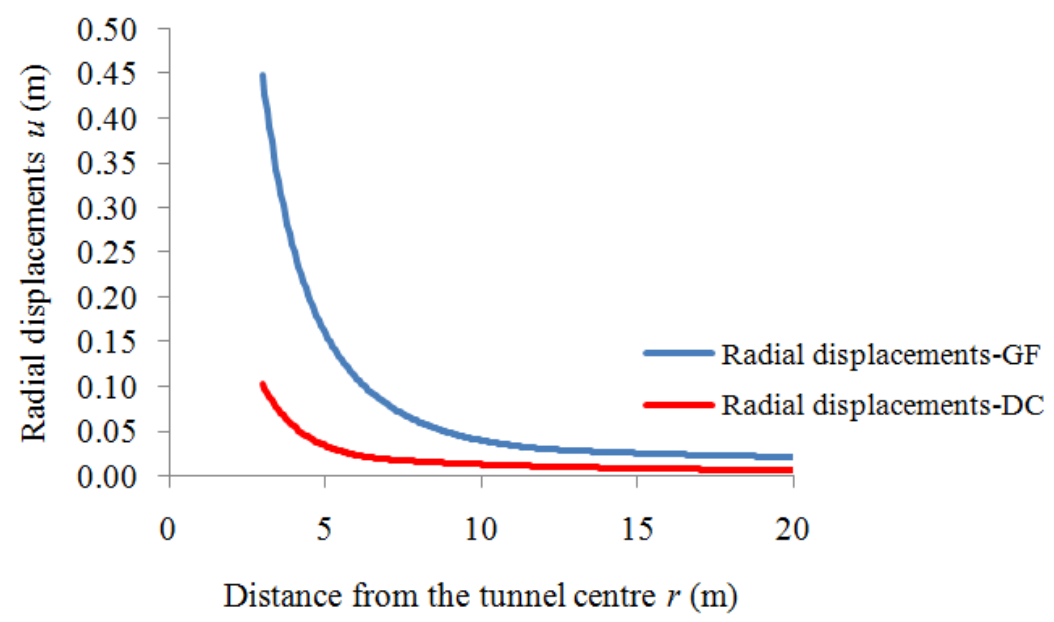

Fig. 5. Trend of the radial displacements u varying the distance from the tunnel center $r$, for the Dry Condition (DC) and in presence of the Groundwater (GF) in the examined case of a tunnel having a radius equal to $3 \mathrm{~m}$. The internal total pressure applied to the tunnel perimeter is nil

\section{Discussion}

From the analysis of the convergence-confinement curve for the studied case (Fig. 2), it is possible to note that the presence of groundwater can significantly modify the stress and strain behavior of the soil around the tunnel. In fact, the convergence-confinement curve in the presence of a steady flow of water towards the tunnel, involves, at constant total pressure applied internally to the tunnel perimeter, values of the radial displacement of the wall much greater than in the case of water flow absent. This has as a consequence a greater load acting on the tunnel lining. The estimated value of the load on the lining can be made by taking the intersection of the convergence-confinement curve of the tunnel with the reaction line of the lining (Oreste, 2014b).
Furthermore, reducing the internal pressure the plastic radius grow faster in the presence of groundwater (Fig. 3). For a nil internal pressure the plastic radius even varies from about $7 \mathrm{~m}$ (dry condition) to about $13 \mathrm{~m}$ (in the presence of the groundwater flow). The presence of a more extensive plastic zone around the tunnel involves a change in the pattern of the stresses (Fig. 4) and of the radial displacements in the soil (Fig. 5).

In conclusion, the presence of the groundwater flow involves a detensioning of the soil, an increase of the thickness of the plastic zone and a substantial increase of the radial displacements around the tunnel.

The effects of the presence of groundwater, therefore, are significant and cannot be neglected.

The calculation method proposed in this study, therefore, allows the analysis of the interaction between 
the groundwater flow and the soil in a simple and effective way, using a finite difference solution. The stresses and strains that are calculated in the soil around the tunnel are able to provide the convergenceconfinement curve of the tunnel in the presence of groundwater and also lead to the evaluation, with some precision, of the thickness of the plastic zone. Furthermore, proceeding with the intersection of the convergence-confinement curve with the reaction line of the lining, it is possible, in a simple way, to evaluate the magnitude of the loads transmitted from the soil to the tunnel lining when a groundwater flow is present.

\section{Conclusion}

The presence of a flow of water in the soil pores towards the tunnel involves a worsening of the stability conditions that cannot be neglected. It is, therefore, necessary to proceed to the evaluation of the stress and strain state that occurs in the soil in the presence of groundwater.

The numerical methods allow to study the complex mechanism of interaction between the water flow in the pores and the soil, but are generally too slow, especially when a the three-dimensional problem is studied.

The analytical methods, which introduce some simplifying assumptions to the problem, are widely used in tunneling and does lead to the evaluation of the stress and strain state in the soil around the tunnel, in a simple and effective way.

A new calculation procedure using a finite differences solution, able to evaluate the stresses and displacements that develop in the soil, in the presence of a water flow in the pores towards the tunnel, is presented in this study. This procedure allows to obtain the convergence-confinement curve of the tunnel in the presence of groundwater and to determine the thickness of the plastic zone varying the internal total pressure applied to the tunnel perimeter.

The implementation of the procedure to a specific case, has allowed to detect the influence that the water flow in the pores has on the stress and strain behavior of the soil and on the pressure-displacement relationship of the tunnel wall.

\section{Funding Information}

The author have no support or funding to report.

\section{Ethics}

This article is original and contains unpublished material. The corresponding author confirms that all of the other authors have read and approved the manuscript and no ethical issues involved.

\section{References}

Bear, J., 1972. Dynamics of Fluids in Porous Media, Volume 1. 1st Edn., American Elsevier Publishing Company, New York, ISBN-10: 044400114X, pp: 764.

Bobet, A., 2003. Effect of pore water pressure on tunnel support during static and seismic loading. Tunnell. Underground Space Technol., 18: 377-393. DOI: $10.1016 / \mathrm{S} 0886-7798(03) 00008-7$

Carranza-Torres, C. and J. Zhao, 2009. Analytical and numerical study of the effect of water pressure on the mechanical response of cylindrical lined tunnels in elastic and elasto-plastic porous media. Int. J. Rock Mechan. Mining Sci., 46: 531-547. DOI: 10.1016/j.ijrmms.2008.09.009

Do, N.A., D. Dias, P. Oreste and I. Djeran-Maigre, 2014. Three-dimensional numerical simulation of a mechanized twin tunnels in soft ground. Tunnelli. Underground Space Technol., 42: 40-51.

DOI: $10.1016 /$ j.tust.2014.02.001

Do, N.A., D. Dias, P. Oreste and I. Djeran-Maigre, 2015. 2D numerical investigation of segmental tunnel lining under seismic loading. Soil Dynamics Earthquake Eng., 72: 66-76. DOI: 10.1016/j.soildyn.2015.01.015

Fahimifar, A., H. Ghadami and M. Ahmadvand, 2014. The influence of seepage and gravitational loads on elastoplastic solution of circular tunnels. ScientiaIranica A, 21: 1821-1832.

Fernandez, G. and J. Moon, 2010. Excavation-induced hydraulic conductivity reduction around a tunnelPart 1: Guideline for estimate of ground water inflow rate. Tunnell. Underground Space Technol., 25: 560-566. DOI: 10.1016/j.tust.2010.03.006

Haack, A., 1991. Water leakages in subsurface facilities: Required watertightess, contractual matters and methods of redevelopment. Tunnell. Underground Space Technol., 6: 273-282.

DOI: 10.1016/0886-7798(91)90138-T

Hwang, J.H. and C.C. Lu, 2007. A semi-analytical method for analyzing the tunnel water inflow. Tunnell. Underground Space Technol., 22: 39-46. DOI: 10.1016/j.tust.2006.03.003

Lembo-Fazio, A. and R. Ribacchi, 1986. Stato di sforzo e deformazione intorno ad una galleria. I Conferenza di Meccanica ed Ingegneria delle rocce, Torino Italy.

Li, P.F., Q. Fang and D.L. Zhang, 2014. Analytical solutions of stresses and displacements for deep circular tunnels with liners in saturated ground. J. Zhejiang Univ. Sci. A, 15: 395-404. DOI: 10.1631 jzus.A1400023

Nam, S.W. and A. Bobet, 2006. Liner stresses in deep tunnels below the water table. Tunnell. Underground Space Technol., 21: 626-635.

DOI: $10.1016 /$ j.tust.2005.11.004 
Oreste, P.P., 2003. Analysis of structural interaction in tunnels using the convergence-confinement approach. Tunnell. Underground Space Technol., 18: 347-363. DOI: 10.1016/S0886-7798(03)00004-X

Oreste, P., 2005a. A probabilistic design approach for tunnel supports. Comput. Geotechn., 32: 520-534. DOI: 10.1016/j.compgeo.2005.09.003

Oreste, P., 2005b. Back-analysis techniques for the improvement of the understanding of rock in underground constructions. Tunnell. Underground Space Technol., 20: 7-21. DOI: $10.1016 /$ j.tust.2004.04.002

Oreste, P.P., 2007. A numerical approach to the hyperstatic reaction method for the dimensioning of tunnel supports. Tunnell. Underground Space Technol., 22: 185-205. DOI: $10.1016 /$ j.tust.2006.05.002

Oreste, P., 2008. Distinct analysis of fully grouted bolts around a circular tunnel considering the congruence of displacements between the bar and the rock. Int. J. Rock Mechan. Mining Sci., 45: 1052-1067. DOI: 10.1016/j.ijrmms.2007.11.003

Oreste, P.P., 2009a. Face stabilisation of shallow tunnels using fibreglass dowels. Institution Civil Eng., 162: 95-109. DOI: 10.1680/geng.2009.162.2.95

Oreste, P., 2009b. The convergence-confinement method: Roles and limits in modern geomechanical tunnel design. Am. J. Applied Sci., 6: 757-771. DOI: 10.3844/ajassp.2009.757.771

Oreste, P., 2013. Face stabilization of deep tunnels using longitudinal fibreglass dowels. Int. J. Rock Mechan. Mining Sci., 58: 127-140.

DOI: 10.1016/j.ijrmms.2012.07.011
Oreste, P., 2014a. Analysis of the tunnel-support interaction through a probabilistic approach. Am. J. Applied Sci., 12: 121-129. DOI: 10.3844/ajassp.2015.121.129

Oreste, P., 2014b. The determination of the tunnel structure loads through the analysis of the interaction between the void and the support using the convergence-confinement method. Am. J. Applied Sci., 11: 1945-1954. DOI: 10.3844 /ajassp.2014.1945.1954

Osgoui, R.R. and P. Oreste, 2007. Convergence-control approach for rock tunnels reinforced by grouted bolts, using the homogenization concept. Geotechn. Geological Eng., 25: 431-440. DOI: $10.1007 / \mathrm{s} 10706-007-9120-0$

Osgoui, R.R. and P. Oreste, 2010. Elasto-plastic analytical model for the design of grouted bolts in a Hoek-Brown medium. Int. J. Numerical Analytical Methods Geomechan., 34: 1651-1686. DOI: $10.1002 /$ nag.823

Panet, M., 1995. Le calcul des tunnels par la méthode convergence-confinement. Presses de l'écolenationale des Ponts et chaussées, Paris.

Ribacchi, R. and R. Riccioni, 1977. Stato di sforzo e deformazione intorno ad una galleria circolare. Gallerie e Grandi Opere Sotterranee, 5: 7-18.

Wang, X., Z. Tan, M. Wang, M. Zhang and H. Ming, 2008. Theoretical and experimental study of external water pressure on tunnel lining in controlled drainage under high water level. Tunnell. Underground Space Technol., 23: 552-560. DOI: $10.1016 /$ j.tust.2007.10.004 